\title{
THE CHALLENGE OF A HYBRID EDUCATION BETWEEN COMPUTER SCIENCE AND DESIGN COMPETENCES IN ITALIAN UNIVERSITY COURSES AND DEGREES
}

\author{
Letizia Bollini \\ Department of Psychology, University of Milano-Bicocca (ITALY)
}

\begin{abstract}
The evolution of the Information and Communication Technologies (ICT) is requiring new competences from professionals and practitioners operating in the field that is now including not only traditional computer science knowledge but also a wide spectrum of user-centered, user interfaces and interaction design skills.
\end{abstract}

About the same time the Italian University system was progressively reformed to adhere to the Bologna Process and Declaration (1999) a manifesto and a initiatives series to build a common European Higher Education Area. Three successive reforms Berlinguer (2000), Moratti (2003) and Gelmini (2010) completely redefined the higher education curricula and opened the system to a wider range of courses based on specific and mixed competences as required in the professional world.

New bachelors and master degrees courses - for example Internet Science at the University of Bologna, Communication and Multimedia at University of Pavia or Digital Communication at the State University of Milan-were established inside traditional department and the people teaching in the new borderline fields had themselves specialized background mainly of the 3 areas: computer science or electronically engineering, architecture and design, cognitive psychology and ergonomic.

Starting from such different perspectives, the question that emerges spontaneously is about the basic and essential skills that students should acquire to be fitted for the professional market that actually requires both traversal abilities to see problems and, at the same time, deep knowledge of specific applications field. According to the contemporary debate about "should designers be able to code" or "programmers should learn to understand user needs and cognitive processes" what is clearly emerging is that traditional divisions are no longer efficient and that a new approach and desirable if not even necessary in the direction of an hybrid, cross-disciplinary education.

Exploring to this new demand of contamination between the technical and the design and humanities cultures the research project "Zero Design Background" investigates, lists, compares and proposes a critical review of the university educational hybrid offer with the aim to map the fundamental competences and principles that students should acquire during the training.

Firstly the paper maps and critically compare the Computer Science (CS), User Experience (Ux) and User Interface (UI) Design courses available for bachelor's and master degree students within the Italian departments of Computer Science; Computer Engineering; Information Technologies; Architecture; Design; Arts and Design: Communication Science; and Psychology to have a clear picture of the state of the art. Secondly the research put in relation the department, degrees course classification, class title and contents, professors cultural background and scientific/disciplinary sector in a matrix to identify and cluster emerging patterns in the educational field to understand potentially and limits and address future developments

Keywords: ITC, Information and Communication Technologies, User Interface Design, User Experience Design, Hybrid education.

\section{INTRODUCTION}

In a world in which technology has enabled tools and devices —once limited to an experts nichesuch as internet and the world wide web to become mass-media even more pervasive than magazines, radio and TV, technology itself should face its new mission.

The introduction in the last decade of mobile devices, wearable, Internet of Things have deeply changed the relationship among people technologies and environment mediated by digital and interactive tools and services.

Internet is pocketable — as appointed by Thomas Husson who firstly used the word in 2008 [1] — and it is a so indispensable part in our every day life that technology must become even more usable, 
friendly, transparent —as stated in the studies published by Bonsiepe [2], Garret [3], Maeda [4], Nielsen [5] and Norman [6] — even funny - according to the new gamification approach to design introduced by Ferrara [7] - not to betray the users' expectations.

In a relatively mature era -although still open and rich of future promises of innovations - technology should focus more on people and their needs, the way they think, communicate, act and interact. Internet -also nominated for Nobel Peace Prize - is probably one of the most important drivers of democratization, social participation, knowledge sharing, information access and platform for dialogue, on the other hand the digital divide - both technological, cultural or political- is the antithetic challenge in which ICT (Information Communication Technologies) plays is plays his bet to become a mass communication tool. This humanization challenge has is roots in the growth of future's designers and developers. Moreover, the next generation of professionals will belong to the so-called digital natives or Millennials. People born after the net revolution who are naturally familiar with digital technologies and devices, a demographic segment probably able to fill the generational gap, a sort of anthropological evolution, between them and the migrant ones [8].

The Italian educational system should therefor faces with the deep challenges both of the professional world and the liquid drift of contemporary society according to Baumann definition [9].

Italy has the lowest numbers of people with an university degree -22,4\% in 2013 looking after the data collected in Eurostats report [10] and compared with the European average of $36,8 \%$ - with a high percentage of dropouts (55\%) and just a $42,7 \%$ of people already working after a year according to Alma Laurea Consortium Research 2015 [11]. Beyond the statistical data, what seems to be relevant is the undoubtable relationship between the research and development potentiality, the national PIL and ability to innovate of younger generations and their level of education. In a postindustrial, post-modern society, no more labour intensive, the strategic assets are represented by intellectual work and educational investment.

Following this issues the Italian University system has been progressively reformed to adhere to the Bologna Process and Declaration (1999) a manifesto and a initiatives series to build a common European Higher Education Area.

The first two legislative reforms - Berlinguer (2000), Moratti (2003) - were aimed to radically transform the Italian system - a 4 to 5 single-cycle master degrees, with the only exception of the 6 years long Medicine MD - creating a BFA/first level-degree offers -the so-called laurea triennalewith a strong professional vocation and a 2 years MFA where students have the opportunity of a higher specialization - the laurea magistrale. The final goals were to have younger people directly entering the work market; a deeper and practical professional preparation; to reduce the school dropouts increasing consequently the number of graduates citizens.

These structural changes completely redefined the higher education curricula and opened the system to a wider range of courses based on specific and mixed competences as required in the professional world. According to this new organization may university enlarge their offers mixed different competences. In particular design, computer science and phycology have benne involved in this new challenge. At the same time the issues proposed by the work market require complex answers.

Training becomes one of the critical assets in which to play the challenge of ICT. Educational programme have traditionally preferred to specialize competences clustering them in main sectors and disciplines, able to prepare future pros in a well-organized Fordism work process show their limits.

Changed were happened also in the structural organization of the design process, moving from a waterfall linear sequence to an agile spiral evolution. Which implies a transversal involvement of human resources and competences in any part of the project. Small interdisciplinary and wellintegrated teams are fundamental to conceptualize, design, develop and test small functioning solutions or services o integrate with subsequent updating of the whole system.

To do that working groups should be composed from the beginning by all the competences, skills and expertise involved to finalize the project to the expected goals Moreover the agile methodology implies the direct and early involvement of users in co-design and evaluation activities.

Consequently people should be able to understand, share and collectively discuss methodologies, technical aspects of the project and user-centered design point of view. People, therefor, need a hybrid culture a deep and updated knowledge in their own field, and a transversal ability to understand other competences and disciplines' issues. According to Manifesto ibridi [12] e driver of this innovation approach are complexity, acceleration, interaction and mind. 


\section{MAPPING THE STATE OF THE ART}

The almost recent evolution introduced by the new university courses organization has created new and varied training opportunities not always coordinated according to a systematic plan. Many of the courses - BFA, MFA or single classes- have been spontaneously organized using local resources and faculties or linking to industrial and professional context. Excellences can be found in very different scenarios but their fragmentation makes it difficult to retrieve and to choose them for the students trying to do a long-term decision for their professional future.

In response to this lack of systematic information the research project "Zero design background" proposes in its initial phase a mapping activity to find and classify the existing offer in the field.

The work started basing its hypothesis and methodological approach on previous studies transversally conducted in the field of design education and its professional follow-up — such as Bonsiepe, 1993 [13], Potter, 2002 [14], Bertola \& Maffei, 2008 [15] and Burkhardt, 2010 [16] — and on research projects focused on the hybrid approach to (visual) design teaching in the ICT field - see Bollini, 2010 [17], 2012 [18] and 2016 [19] — mixing different levels of inquiring.

On one hand it is aimed to identify issues able to describe this world blanching between technology and hard science, humanities social and ergonomic methods and the specificity of design training and education. The research project covers different aspects trying to identify the "new" principles of an eidomatic digital basic design according to the work of Anceschi \& Marini [20] and the recent book of Ellen Lupton and Jenifer Cole Phillips graphic design: the new basic [21]. To cover this aspects the research plan included a literature review of books and manuals in the field of digital design [19], on line resources and community of practice, on line MOOC and long-life learning experiences. The paper introduces in particular the work made to map, catalogue and interpret the university teaching field.

\subsection{Method}

The research track on BFA/MFA courses start mapping and analysing a multi dimensional matrix including:

\subsubsection{Department where courses or classes in Ux/UI Design are activated}

Many different departments have activated courses in the field of Ux/UI Design or have single classes inside BFA/MFA curricula. In particular - as shown in figure 1- it is possible to cluster them in some main macro-sector:

- Design (33\%): Art and design, Art, Industrial Design.

- Informatica (24\%): Computer science, informatics

- Psicologia (26\%): Psychology, Cognitive ergonomic, Social Science, Educational Science

- Ingegneria (12\%): Electronic-, Informatics-, Engineering

- Lettere (5\%): Literature, Communication

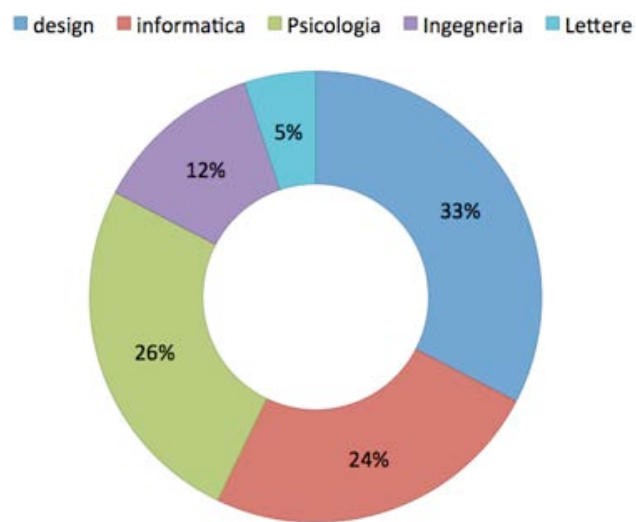

Fig 1. The graph shows the distribution of BFA/MFA in university department. 


\subsubsection{Background of faculty and lecturer teaching UX/UI design in this classes}

Many of the faculty — considered they are digital migrants — have hard science background — such as math, physic, electronic engineering - project culture background - mainly architects or designersor humanities/social background - psychologist, cognitive ergonomic experts, social psychologists, ethnographers, human computer interaction experts and so on- as reported in figure 2.

L 04 (disegno industriale)
L 08 (ingegneria dell'informazione)
L 20 (scienze della comunicazione)
L 24 (scienze e tecniche psicologiche)
L 31 (scienze e tecnologie informatiche)

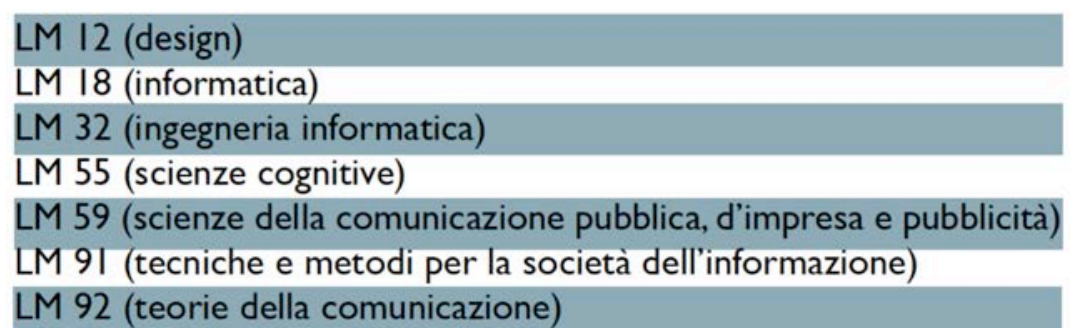

Fig 2. The table shows the MIUR classification of BFA/MFA.

\subsubsection{Scientific-disciplinary sector (SSD)}

Single courses and classes where listed according to the classification of Italian Education, University and Research Ministry as shown in figure 3.

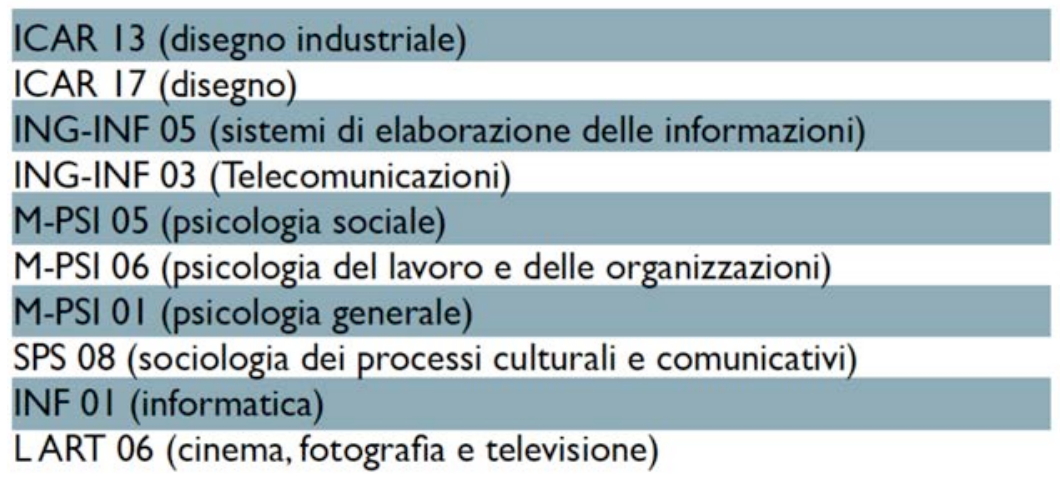

Fig 3. The table shows the MIUR classification of Scientifi-disciplinary sector.

In particular discipline mainly involved are:

- Civil Engineering and Architecture (ICAr): industrial design; drawing/visual representation

- Informatics Engineering (ING-INF): information processing; Telecommunication

- Historical, phylosophical, pedagogical and pscyhologycal science (M-PSI): Social psychology; Psychology of work and organizations, Psychology

- Social and Political Science (SPS): Scociology of the Cultural and communicational processes

- Computer Science (INF): Computer Science

- Antiquities, Phylological-literature, historical-artistical science (LART): cinematography; photography; television 


\subsubsection{BFA/MFA area and SSD correspondences}

BFA (L) and MFA (LM) classification have been matched with the SSD to understand recursive pattern or disciplines clusters according to classification in figure 4 below.

\begin{tabular}{|c|c|}
\hline $\begin{array}{l}\text { L } 3 \text { I Scienze e Tecnologie Informatiche } \\
\text { LM I } 8 \text { Informatica }\end{array}$ & INF 0 I Informatica \\
\hline $\begin{array}{l}\text { L } 20 \text { Scienze della Comunicazione } \\
\text { LM } 92 \text { Teorie della Comunicazione }\end{array}$ & $\begin{array}{l}\text { SPS } 08 \text { Sociologia dei Processi Culturali e } \\
\text { Comunicativi }\end{array}$ \\
\hline $\begin{array}{l}\text { L } 08 \text { Ingegneria dell'Informazione } \\
\text { LM } 32 \text { Ingegneria Informatica }\end{array}$ & $\begin{array}{l}\text { ING INF } 05 \text { Sistemi di Elaborazione } \\
\text { delle Informazioni } \\
\text { ING INF } 06 \text { Bioingegneria Elettronica } \\
\text { e Informatica }\end{array}$ \\
\hline $\begin{array}{l}\text { L } 04 \text { Disegno Industriale } \\
\text { LM I } 2 \text { Design }\end{array}$ & $\begin{array}{l}\text { ICAR } 13 \text { Disegno Industriale } \\
\text { ICAR } 17 \text { Disegno } \\
\text { ISDE } 03 \text { Design dei Sistemi } \\
\text { ISDC } 04 \text { Progettazione Multimediale } \\
\text { ISDC } 07 \text { Tecniche Informatiche Multimediali }\end{array}$ \\
\hline LM 55 Scienze Cognitive & $\begin{array}{l}\text { M PSI } 0 \text { I Psicologia Generale } \\
\text { M PED } 03 \text { Didattica e Pedagogia } \\
\text { Speciale }\end{array}$ \\
\hline $\begin{array}{l}\text { L } 2 \text { I Scienze della Pianificazione } \\
\text { Territoriale, Urbanistica, Paesaggistica } \\
\text { e Ambientale } \\
\text { L } 10 \text { Lettere }\end{array}$ & $\begin{array}{l}\text { SECS P } 01 \text { Economia Politica } \\
\text { LART } 06 \text { Cinema Fotografia e } \\
\text { Televisone }\end{array}$ \\
\hline
\end{tabular}

Fig 4. The table shows the corrispndence between SSD and single.

\subsubsection{Programme and emerging tag/key words of the class description}

A card reporting the main information of each class have been produced to compare every single course according to: SSD; University; Department; BFA/MFA area; course title; class title; and a synthetic text describing the class as presented in the Guida dello studente (Student's guide) and/or the offiical on-line presentation on the university web site.

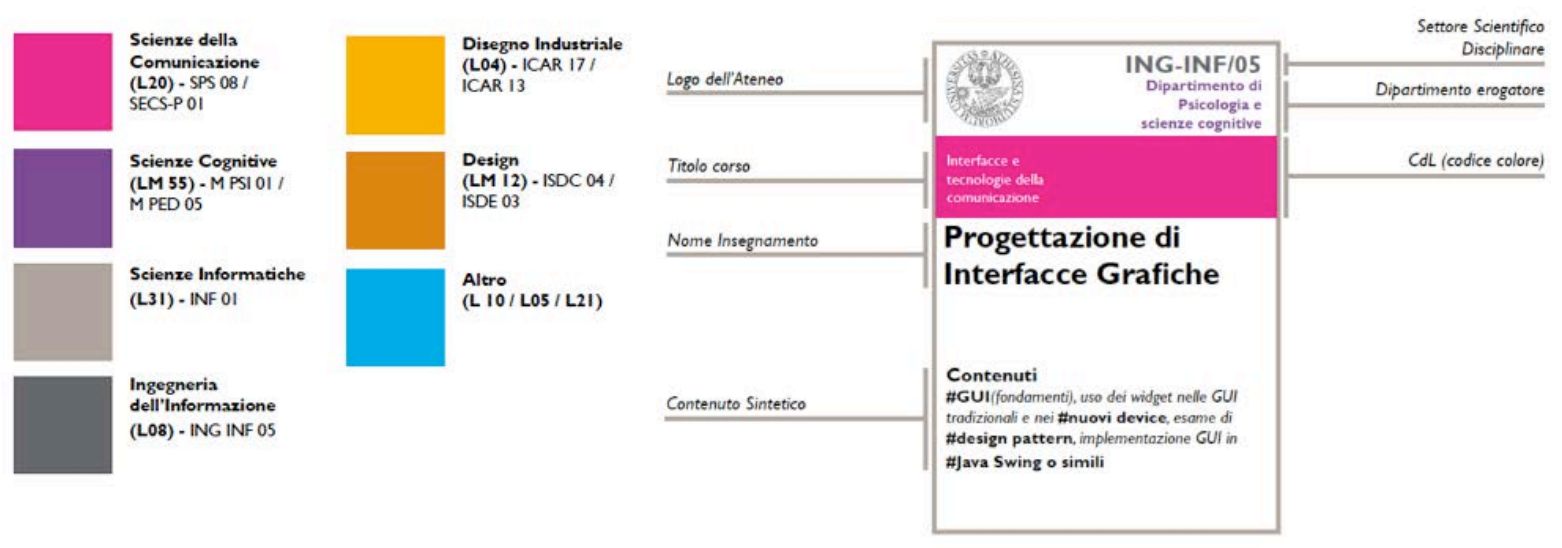

Fig 5. The class card describing the main infrmation and the SSD color tag.

\subsection{Findings}

Three different visualization have been realized to show and compare the date. The first bar chart shows which classes have been mapped inside the BFA/MFA area among the selected sample according and highlighted using the colour tag compared to the SSD represented by its color tag too. The second bar chart shows the classes corrisponding to the same SSD and the distribution inside the 
sample accordind to the BFA/MFA where they are held. The third map represents the distribution of the single classes inside the BFA/MFA courses and the relevance with the $U x / U I$ design disciplines.

L 31 ( 14 elementi) LM 18 ( 5 elementi)

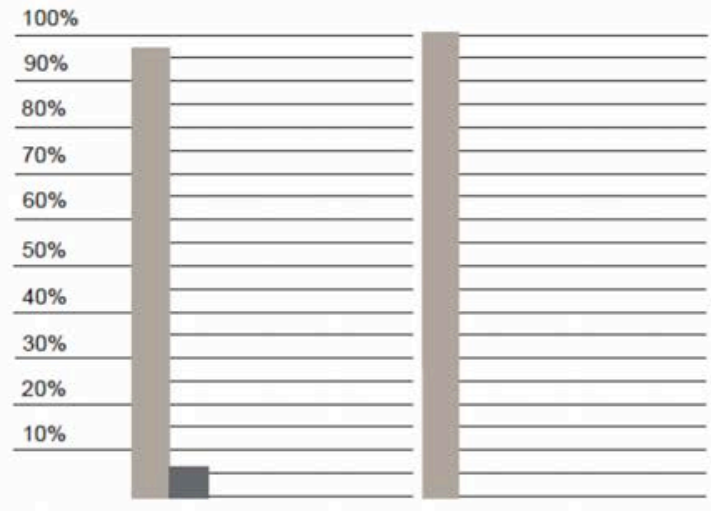

L 08 (I elemento) LM 32 (4 elementi)

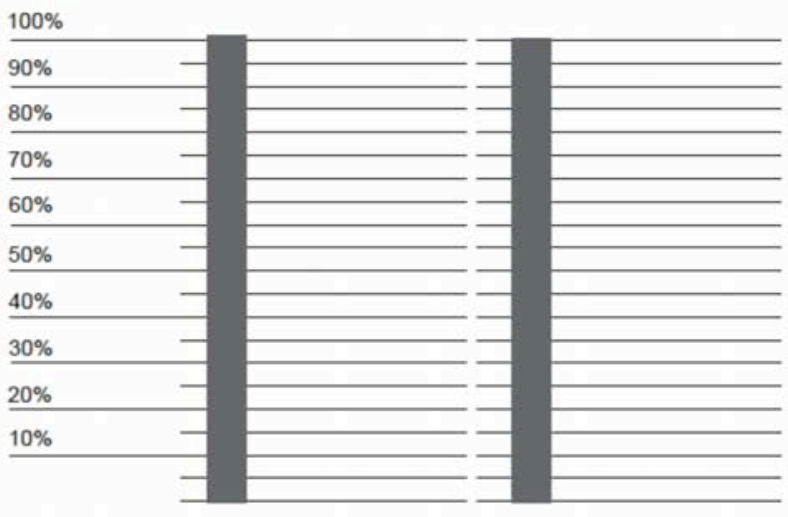

$-21$

$\mathrm{LIO}$

L04 LMI2
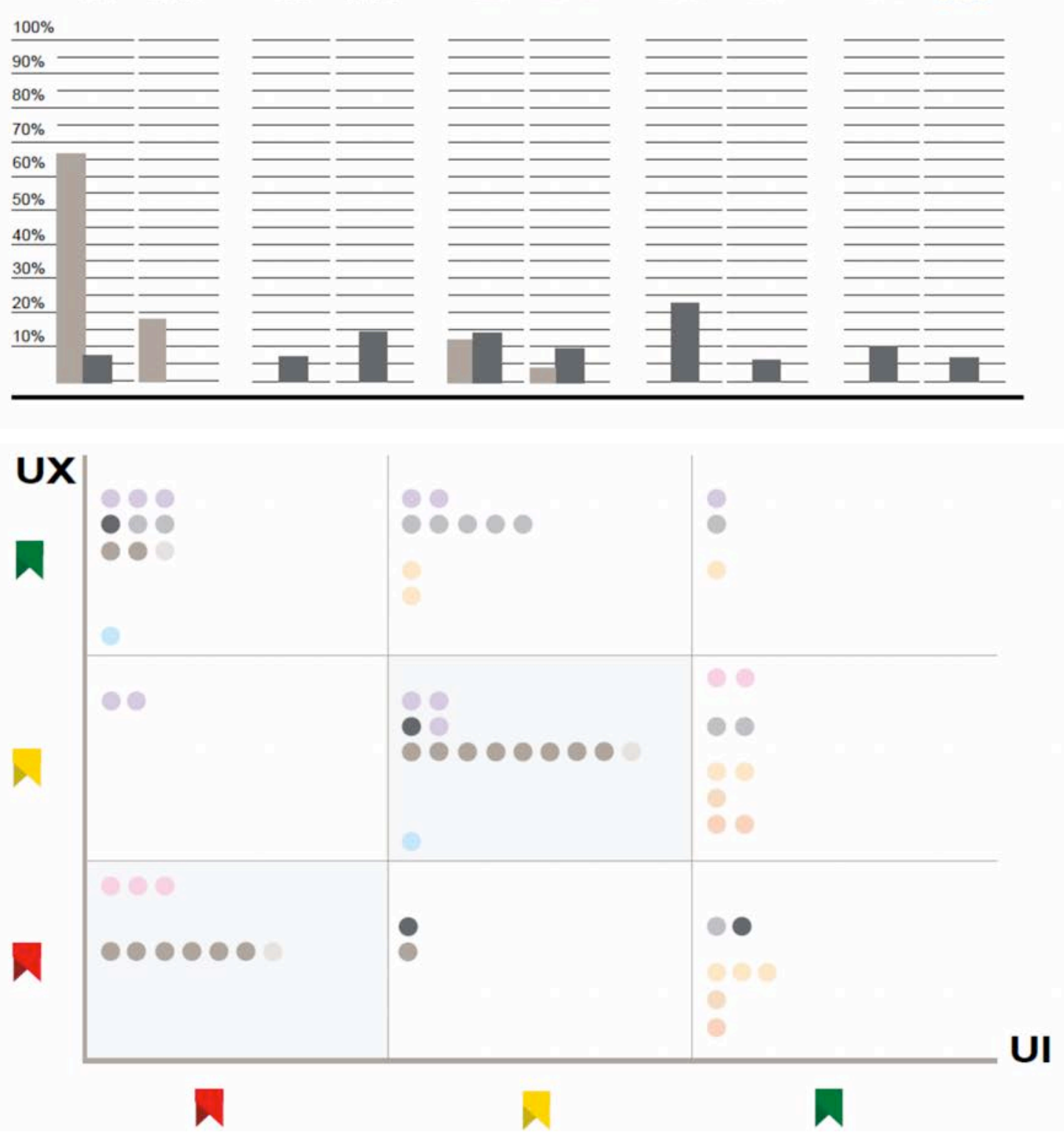

Fig 6. Chart referred to the Computer Science area. 
LIO (4 elementi) L2I (I elemento)
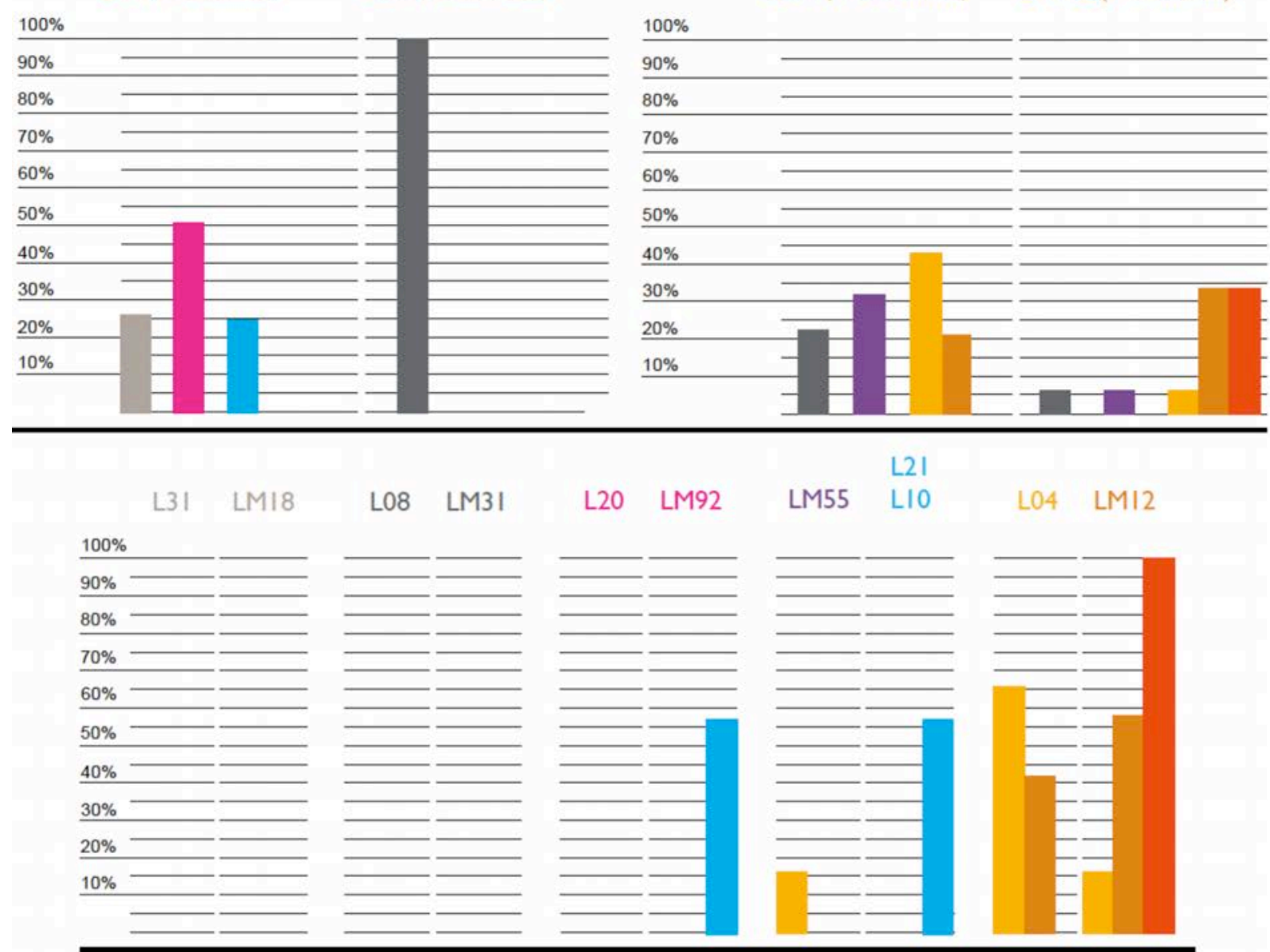

\section{UX}

,

๑

O 10

O 1

5

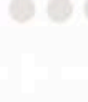

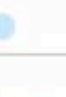

$\bullet$

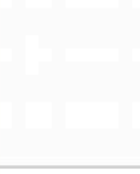

-
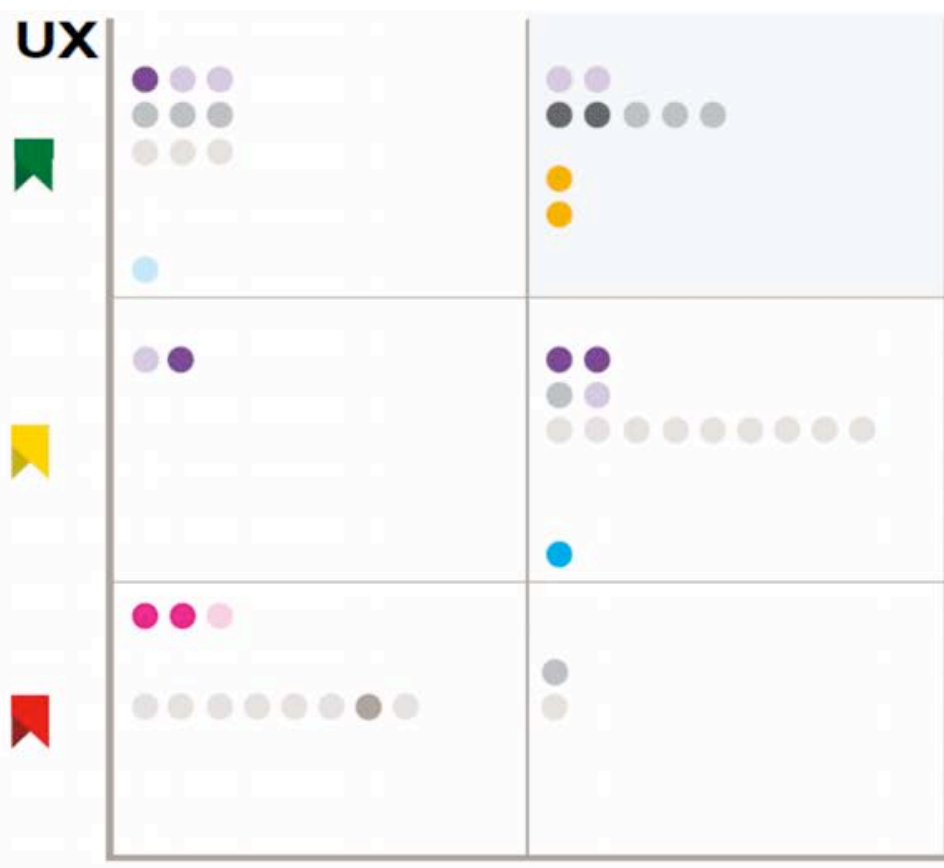

C

(9)

○

Fig 7. Chart referred to the Design area. 
LM 55 (7 elementi)

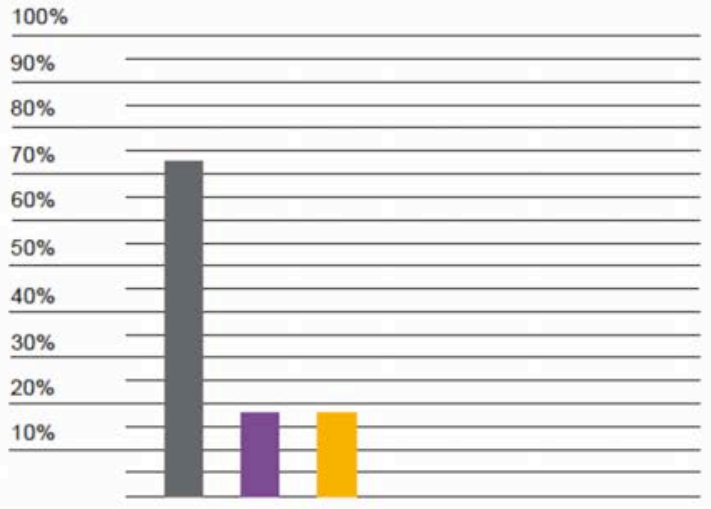

L 20 ( 10 elementi) LM 92 ( 9 elementi)

$100 \%$

$90 \%$

$80 \%$

$70 \%$

$60 \%$

$50 \%$

$40 \%$

$30 \%$

$20 \%$

$10 \%$

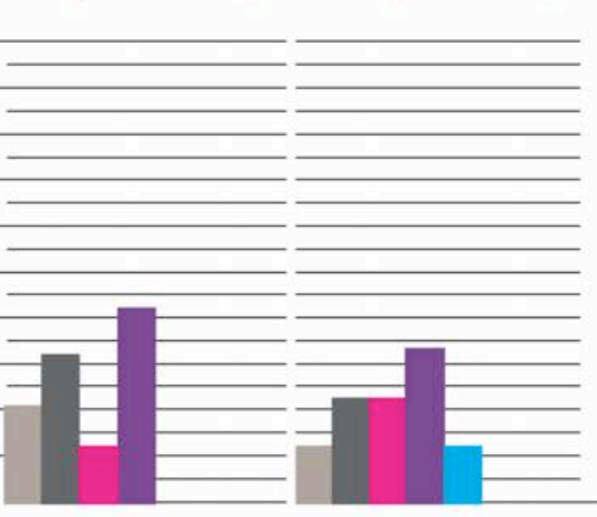

L2I
LIO
L04 LMI2
L3।
L08 LM3I
L20 LM92
LM55
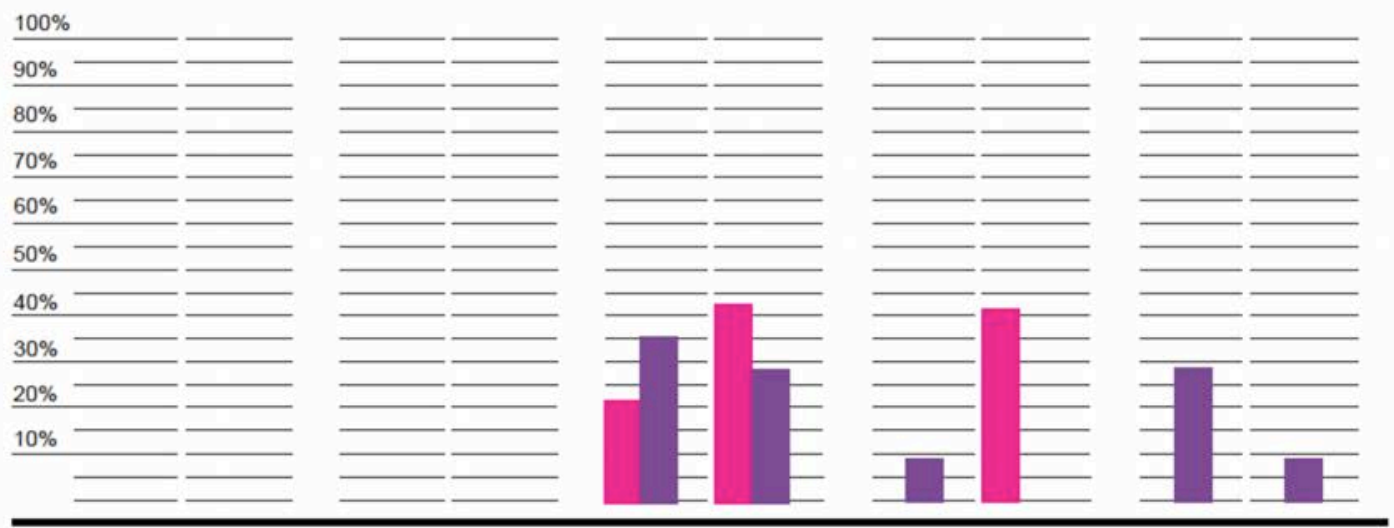

\section{UX}

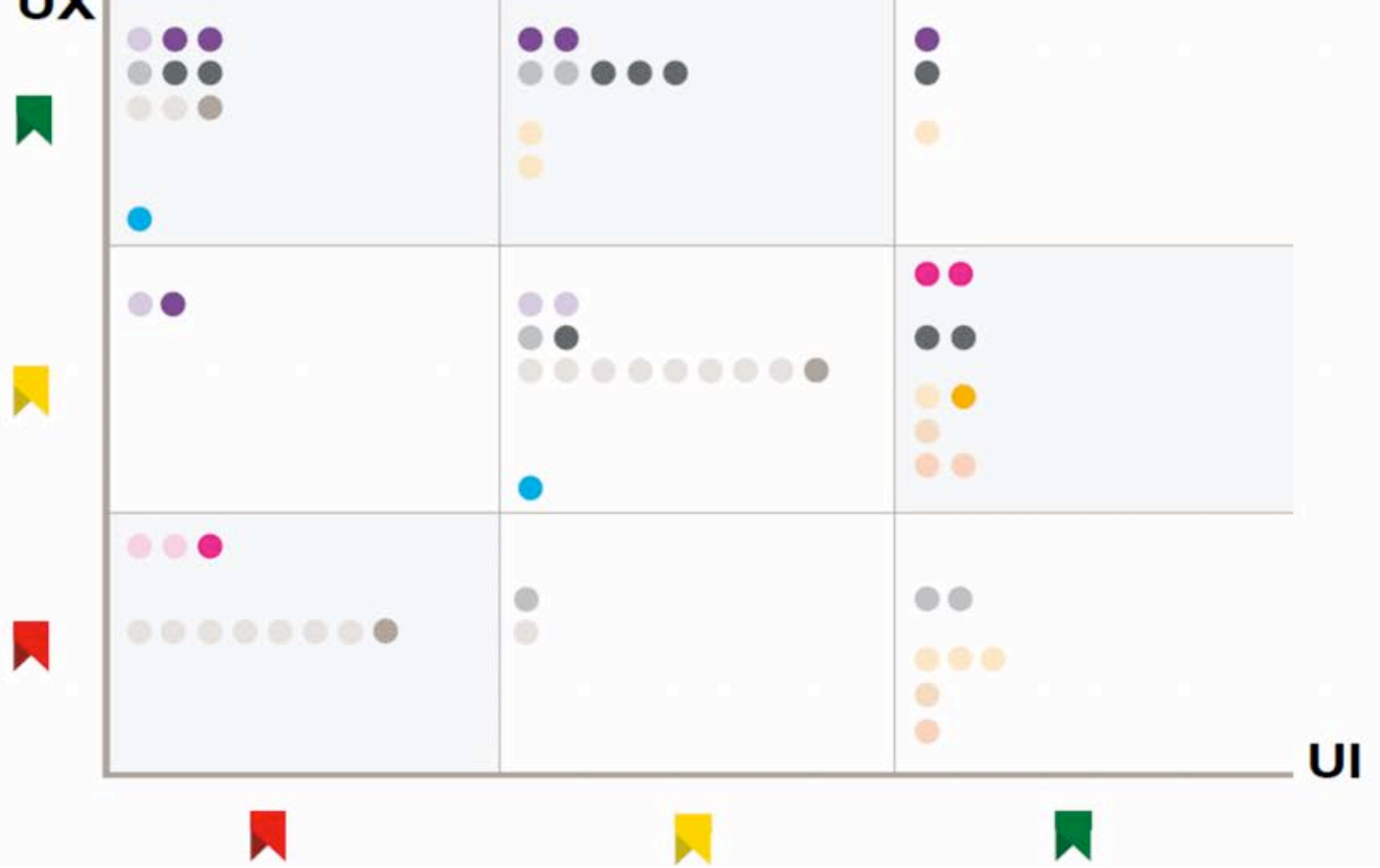

Fig 8. Chart referred to the Psychology area. 


\section{CONCLUSIONS}

This first overview of the Italian university offers in the field of UXD e UID still presents a strong disciplinary uniformity between courses and department although underline -on the opposite- a more variable matching between the background of the professors and the topics taught. Nevertheless the educational offers are still far away of a hybrid configuration of skills, methods, professional cultures and disciplinary approaches. The field is still young and official institution a rarely the "early adopters" or at least the innovators in such challenges. Probably in a couple of generation, when younger people and/or digital natives would be involved in university course we'll assist a migration of knowledge among the disciplinary boundaries now established.

\section{ACKNOWLEDGMENT}

I would like to thank Pietro Tedeschi Polmonari author of the degree thesis in Communication and Psychology: Corsi e insegnamenti di User Experience Design e User Interface Design nelle Università italiane: una mappatura critica at University of Milano-Biccoca from which the figures 2, 3 and 4 have been taken.

\section{REFERENCES}

[1] Husson, T. (2013). Forrester Research. The Wall Street Journal: https://www.forrester.com/2013+Mobile+Trends+For+eBusiness+Professionals/fulltext/-/ERES91241 (Last visited: 13rd February 2016).

[2] Bondsiepe, G. (1993). Il ruolo del design. In G. Anceschi (Ed.) /l design dellinterazione. Milano: Domus Academy.

[3] Garrett, J. J. (2002). The elements of User Experience Design. Berkley: Peachpit Press.

[4] Maeda, J. (2006). The laws of simplicity. Cambridge: The MIT Press.

[5] Nielsen, J. (1998). The invisible computer. Why Good Products Can Fail, the Personal Computer Is So Complex and Information Applicances Are the Solution. Cambridge: The MIT Press.

[6] Norman, D. (2013) The Design of everyday things. Revised and expanded Edition New York: Basic Books.

[7] Ferrara, J. (2012). Playful Design: Creating Game Experiences in Everyday Interfaces, San Francisco: Rosenfeld Media.

[8] Bollini, L. (2015). Learning by playing. A gamification approach to a language-learing digital tool. In ICERI 2015 pp. 5271-5278. IATED: Seville.

[9] Bauman, Z. (2006). Modernità liquida. Bari: Laterza.

[10] http://www.ilsole24ore.com/pdf2010/Editrice/ILSOLE24ORE/ILSOLE24ORE/Online/_Oggetti_C orrelati/Documenti/Notizie/2014/04/numeri-eurostat-ritardo-italiano.pdf (Last visited: 2 nd May 2016).

[11] https://www2.almalaurea.it/cgi-php/lau/sondaggi/intro.php?config=occupazione (Last visited: 2nd May 2016).

[12] Giacoma, G., Bocchi, G., Damiano, L. \& Casali, D. (2012). Manifesto ibridi http://manifestoibridi.org/explanation/it (Last visited: 13rd February 2016).

[13] Bonsiepe, G. (1993) Teoria e prassi del disegno industriale. Elementi per una manualistica critica. Milano: Feltrinelli.

[14] Potter, N. (2002). What is a designer. London: Hyphen Press.

[15] Bertola, P. \& Maffei, S. (2008). DRM - Design Research Map. Milano: Poli.Design.

[16] Burkhardt, F. (October 2013). "Il designer come apprendista: l'importanza di una formazione dal basso" AIS/Design Storia e Ricerche, vol. 2.

[17] Bollini, L. (2010). Learning by doing: a user centered approach to signage design. Milano Bicocca a case study, EDULEARN10 Proceedings, 3090-3097. 
[18] Bollini, L. (2012). Visual design for non-designers. A participatory experience based on web 2.0 tools in a multidisciplinary master degree programme. In Proceedings INTEND 2012 conference. Valencia: IATED, pp. 3157-3162.

[19] Bollini, L. (2016). Teaching Visual and User Interface design in ICT field. A critical review of (digital) design manuals. INTED 2016.

[20] Anceschi, G. \& Marini, D. (1987). Manifesto eidomatico (e qualche esempio), W.W.N. 7, giugno 1987, pp. 7-9.

[21] Lupton, E. \& J. C. Phillips, J. C. (2015) Graphic design: the new basic, $2^{\text {nd }}$ Ed. Princeton Architectural Press.

[22] Garret, J. J. (2001). The element of User Experience, San Francisco: New Riders.

[23] Norman, D. A. (2007). Emotional design. Perché amiamo (o odiamo) gli oggetti della vita quotidiana. Milano: Apogeo. 